\title{
Factors Associated with Smoking and Alcohol Consumption among Street Vendors in the Metropolitan Area of Bucaramanga, Colombia
}

\author{
Reynaldo Mauricio Rodríguez Amaya ${ }^{1}$ \\ ${ }^{1}$ SARET research group, Manuela Beltrán University at Bucaramanga, Colombia \\ Correspondence: Reynaldo Mauricio Rodríguez Amaya, Professor and Researcher, SARET research group, \\ Manuela Beltrán University at Bucaramanga, Colombia.
}

\author{
Received: May 8, 2018 Accepted: June 18, 2018 Online Published:August 23, 2018 \\ doi:10.5539/gjhs.v10n9p103 URL: https://doi.org/10.5539/gjhs.v10n9p103
}

\begin{abstract}
Aim: The objective of the study was to characterize, learn and establish related factors about the behavior of alcohol and tobacco consumption in a sample of street vendors in the Metropolitan Area of Bucaramanga, Colombia.

Methods: A descriptive cross-sectional study was conducted on 425 street vendors. With regard to sampling, a non-probability sampling was conducted on the streets of every city in the Metropolitan Area. Each worker was given a questionnaire that included socio-demographic and occupational variables, in addition it was applied the Fagerstrom test was applied along with the Alcohol Use Disorders Inventory Test (AUDIT).

Results: Twenty one percent of the workers reported being consumers of cigarettes, $57 \%$ had consumed alcohol and $17 \%$ had both habits; consuming liquor and cigarettes. As for consumption of harmful liquor, men had higher risk (OR $2.97 p=.001)$, the age of highest consumption was between 18-39 years $($ OR $1.3 p=.01)$ and smokers had a significant risk (OR $4.33 p=.001)$. According to the logistic regression model, among the main factors associated with harmful alcohol use they were: male gender, not having health insurance, smoking and living in the main city of the Metropolitan Area.

Conclusion: Street vendors have certain socio-demographic and labor variables that lead to raising their vulnerability. As for their spending habits, they have a high consumption of cigarettes and alcohol in relation to other group of workers, however the level of dependence is not superlative. In those who had detrimental alcohol consumption, the most important related variables to intervene were insufficient health coverage and smoking.
\end{abstract}

Keywords: alcoholism, smoking, street vendors, occupational health

\section{Introduction}

In recent decades, the concept of informal work has taken several definitions, the International Labour Organization (ILO) has defined the informal sector as employment that lacks a legal or social protection, this situation will result in an increase in risks of workers in the non-consolidation of optimal, physical, mental, social and economic welfare. In turn, there are a number of sub-categories within the informal sector, as defined in the International Classification of Status in Employment (ICSE-93) (International Labour Organization, 2003).

Likewise, the ILO in its most recent publications includes informal work as a vulnerable work, for instance, informal work on the street can involve a violent environment depending on the location of the city and the time of the work, another highlight is the economic instability that these workers are exposed to by not having a fixed salary. Consequently, it is seen that this kind of works is the most frequent in countries under development (Kusakabe, 2006). Similarly, the ILO puts Colombia as the third Latin American country with the highest proportion of informal workers, not being very far from the figures of Bolivia and Peru, which have higher rates reaching almost $80 \%$ of employees. Also, it has been reported that informal employment has begun to increase again, particularly in some transition economies such as Eastern Europe and Central Asia, evenly, in Africa, the street vendors are a significant proportion of urban employment, including South Africa, but less in India and Vietnam and even less in Latin America (International Labour Office, 2013).

The phenomenon of informality at work in Latin America is not a new situation, and particularly in Colombia for decades has been presented on the rise, at a time it was thought that informality would disappear, but the opposite has occurred (DANE, 2014). The National Department of Statistics of Colombia (DANE) has estimated that the 
proportion of informal engaged in the thirteen Metropolitan Areas in Colombia was $48.5 \%$ for the quarter from March to May 2014, as well as the branch of activity, $42.2 \%$ informal working population work concentrated on trade, hotels and restaurants. Also, considering the occupational position, the self-employed accumulated $60.1 \%$ of the informal working population (DANE, 2009). Moreover within the academic literature in street workers have been concerned with the study of environmental risks that the worker on the street is exposed (ultraviolet rays, carbon dioxide), others have investigated the hygiene conditions of food that these workers prepare and sell (Viveros, Vivas, \& Guerrero, 2014), however few publications focus on the study of the workers behavior about mental health problems as the consumption of alcohol and cigarettes and likely risk of addiction to these substances.

In Colombia, in street vendors it has been found alcohol consumption values close to $40 \%$ and between 6 to $30 \%$ in the consumption of cigarettes (Viveros, Vivas \& Guerrero, 2014; Botina, Cabrera, Erazo, Guerrero, Ibarra \& Vallejo, 2011). In countries such as Ecuador it has been found that street vendors in a market sale have figures in alcohol consumption that reached $22.6 \%$ with a risk of harmful consumption at $0.9 \%$ and on the other hand cigarette consumption was approximately 3\% (Guallpa, 2014). It is important to highlight that in these publications the consumption is not determined by a scale but by scarce questions with simple answers without an appropriate psychometric focus. Similarly, in Latin American publications alcoholism stands out among the main problems of street vendors, but they do not deepened in the measurement and description by levels (Contreras, González, \& León, 2014). On the other hand, available publications in Asia and Latin America tend to focus especially in psychosocial disorders such as depression, suicide and social issues as inequality, unemployment or poorly paid employment (Moyano, Guevara, \& Lizana, 2008). Therefore, during the last several years within the Occupational Health Graduate and Post-graduate Programs at Manuela Beltran University at Bucaramanga, there has been a heightened interest in identifying the need to develop research on healthy lifestyles in the informal sector. In this sense, a study was conducted for identify consumption, possible dependence and related factors on alcohol and cigarette among informal workers who work on the streets of Bucaramanga and the Metropolitan Area.

\section{Methods}

\subsection{Design and Population Study}

A descriptive cross-sectional study was conducted in 2014; the target population was 425 street vendors. The place where participants were selected was the city of Bucaramanga, which is the capital of the department (or State) of Santander, plus were included the towns of Floridablanca, Piedecuesta and Girón, which are part of the Metropolitan Area of the provincial capital city. The Metropolitan Area of Bucaramanga includes approximately 1 200000 inhabitants, also the State has one of the best development rates of the country (DANE, 2013; DANE, 2014).

\subsection{Techniques and Tools for Data Collection}

With regard to sampling, a non-probability sampling was conducted on the streets of every city in the Metropolitan Area. With respect to the recruitment of participants, the workers answered the survey in a face-to-face interview with the interviewers, if the worker had any doubt about filling out the questionnaire; the interviewer was pending to answer any questions, in addition the interviewer was entrusted to check that each questionnaire was fully completed. In addition, anonymity was assured during the interview.

Each worker was given a questionnaire that included demographic and occupational variables; in addition the Fagerstrom test and the Alcohol Use Disorders Inventory Test (AUDIT) were applied. The AUDIT test was developed by the $\mathrm{WHO}$ as a simple method of screening for excessive drinking (Babor, Higgins-Biddle, Saunders, \& Monteiro, 2009).

The AUDIT test includes questions such as: How often do you have a drink containing alcohol?; How many drinks containing alcohol do you have on a typical day when you are drinking?; How often during the last year have you needed a first drink in the morning to get yourself going after a heavy drinking session?. On the other hand, the Fagerstrom test includes questions such as: How soon after you wake up do you smoke your first cigarette?; Do you find it difficult to refrain from smoking in places where it is forbidden?; Which cigarette would you hate most to give up?; How many cigarettes/day do you smoke?

The AUDIT test is divided into 4 sections or Zones. Thus, Zone 1 is between 0 and 8 points and is interpreted as a low risk area, zone 2 is from 8 to 15 points and is considered as low risk zone under consumption, the third area is concentrated between 16 to 19 points interpreted as harmful drinking area and finally, zone 4 has scores above 20 and is interpreted as a zone of probable dependence. In order to set the frequency an dependence of smoking, the 
Fagerstrom test was carried out, an instrument with adequate psychometric properties to address consumption and dependence on this substance (Wellman et al., 2006) (Becoña, Vasquez FL 1998) (Heatherton, Kozlowsy, Frecker \& Fagerstrom 1991)

\subsection{Ethical Considerations}

According to the National and international laws, it was taken into account ethical considerations relevant to such studies. The development of the study had the ethical considerations of the Declaration of Helsinki and Resolution No. 008430 of the Ministry of Health of Colombia that were the basis for developing the written informed consent (Minister of Health, Republic of Colombia, 1993) (World Medical Association, 2013).

\subsection{Analysis of Data}

For the descriptive analysis, proportions for categorical variables were shown with their respective confidence intervals, according quantitative variables were calculated mean and standard deviation $(S D)$. As for the bivariate analysis, measures of association Odds Ratio $(O R)$ were presented evaluating the significant differences by chi2 or Fisher test if required by the distribution of the data. Also a model of logistic regression was performed to assess the strength of association of the leading independent variables. The variables with $p$ values $<0.2$ was included in the model.

\section{Results}

Finally 425 street vendors were interviewed; the average age was $41.9 \pm 14.8$. According to Table 1 , the age group with the most frequency was concentrated in those between 18 to 39 years with almost about half of the participants. In turn, it female participation was greater and in terms of level of schooling, high school level as the most frequent stood out. By marital status, most are married or cohabiting. Considering labor variables, the average of hours by month worked was $235.5 \pm 92.1$, with a median of 240 hours. As for work experience in years in this job, an average of 11 years \pm 11 and a median of seven years were found. Moreover, Table 1 provides information about the labor accidents, the proportion of assured workers in Occupational Risk Administrator (ORA) and finally it shows the frequency of alcohol consumption and smoking.

Table 1. Sociodemographic and work variables on street vendors in the Metropolitan Area of Bucaramanga

\begin{tabular}{lllll}
\hline \multirow{2}{*}{ Variables } & \multicolumn{3}{c}{$\mathbf{C I}$} \\
\cline { 2 - 6 } & $\mathbf{n}$ & $\mathbf{\%}$ & & \\
\hline Age & & & & \\
$60-82$ & 57 & 13.41 & .10 & .16 \\
$40-59$ & 169 & 39.76 & .35 & .44 \\
$18-39$ & 199 & 46.82 & .42 & .51 \\
\hline Gender & & & & \\
Female & 220 & 51.76 & .46 & .56 \\
Male & 205 & 48.24 & .43 & .53 \\
\hline Level of Education & & & & \\
High School & 190 & 44.71 & .39 & .49 \\
Primary level & 178 & 41.88 & .37 & .46 \\
No schooling & 7 & 1.65 & .004 & .02 \\
Technical study and Technology & 33 & 7.76 & .05 & .1 \\
University & 17 & 4.00 & .02 & .05 \\
\hline Marital status & & & & \\
Married-/Free Union & 251 & 59.20 & .54 & .63 \\
Single & 118 & 27.83 & .23 & .32 \\
Widower/ Divorced. & 55 & 12.97 & .09 & .16 \\
\hline
\end{tabular}




\begin{tabular}{lllll}
\hline Work Accident & & & & \\
No & 400 & 94.56 & .92 & .96 \\
Yes & 23 & 5.44 & .03 & .07 \\
\hline Occupational Risk Administrator & & & & \\
No & 360 & 84.71 & .81 & .88 \\
Yes & 65 & 15.29 & .11 & .18 \\
\hline Smoke and Consume Alcohol & & & & \\
No & 353 & 83.06 & .79 & .86 \\
Yes & 73 & 16.94 & .13 & .2 \\
\hline
\end{tabular}

Table 2 shows the consumption of alcohol and smoking disaggregated by the different sociodemographic and labor variables. Initially to cigarette consumption, this is above $50 \%$ in all three age groups established. According to gender, the greater consumption of alcohol was in men. Given the level of schooling, alcohol consumption rate varies between 42 and $60 \%$. Regarding the civil status, two-thirds were married or living with a partner and reported having consumed alcohol. Likewise, those without health coverage had increased consumption of alcohol Finally, in terms of hours worked the group with the most consumers are the ones who work more than 220 hours a month.

Table 2. Sociodemographic and labor variables according to the consumption of alcohol and cigarettes in the street vendors in the Metropolitan Area of Bucaramanga

\begin{tabular}{|c|c|c|c|c|c|c|}
\hline \multirow[t]{2}{*}{ Variables } & \multicolumn{3}{|c|}{ Alcohol Consumption n=242 } & \multicolumn{3}{|c|}{$\begin{array}{c}\text { Smoking } \\
\mathrm{n}=92\end{array}$} \\
\hline & $\%$ & CI & & $\%$ & CI & \\
\hline \multicolumn{7}{|l|}{ Age Groups } \\
\hline $18-39$ & 56,7 & $49,8 \%$ & $63,7 \%$ & 25,1 & 19 & 31,1 \\
\hline $40-59$ & 57,9 & $50,0 \%$ & $65,0 \%$ & 18,3 & 12,4 & 24,2 \\
\hline $60-82$ & 54,3 & $41,0 \%$ & $67,0 \%$ & 19,2 & 8,9 & 29,6 \\
\hline \multicolumn{7}{|l|}{ Gender } \\
\hline Female & $45,9 \%$ & $39,0 \%$ & $52,0 \%$ & 12,7 & 8,3 & 17,1 \\
\hline Male & $68,7 \%$ & $62,0 \%$ & $75,0 \%$ & 31,2 & 24,8 & 37,5 \\
\hline \multicolumn{7}{|l|}{ Level of Education } \\
\hline High School & $57,0 \%$ & $50,0 \%$ & $64,0 \%$ & $25,3 \%$ & $19,1 \%$ & $31,5 \%$ \\
\hline Primary level & $60,0 \%$ & $52,0 \%$ & $67,0 \%$ & $20,8 \%$ & $14,8 \%$ & $26,8 \%$ \\
\hline No schooling & $57,0 \%$ & $17,0 \%$ & $96,0 \%$ & $14,3 \%$ & $-13,8 \%$ & $42,4 \%$ \\
\hline Technical study and Technology & $42,0 \%$ & $25,0 \%$ & $59,0 \%$ & $9,1 \%$ & $-0,9 \%$ & $19,1 \%$ \\
\hline University & $47,0 \%$ & $22,0 \%$ & $71,0 \%$ & $17,6 \%$ & $-1,1 \%$ & $36,4 \%$ \\
\hline \multicolumn{7}{|l|}{ Marital Status } \\
\hline Married-/Free Union & $65,0 \%$ & $56,0 \%$ & $68,0 \%$ & $23,1 \%$ & $17,9 \%$ & $28,3 \%$ \\
\hline Single & $43,0 \%$ & $33,0 \%$ & $51,0 \%$ & $20,3 \%$ & $13,0 \%$ & $27,7 \%$ \\
\hline Widower/ Divorced. & $61,0 \%$ & $48,0 \%$ & $74,0 \%$ & $16,4 \%$ & $6,5 \%$ & $26,3 \%$ \\
\hline \multicolumn{7}{|l|}{ Occupational Risk Administrator } \\
\hline No & $56,0 \%$ & $51,0 \%$ & $61,0 \%$ & $22,8 \%$ & $18,4 \%$ & $27,1 \%$ \\
\hline Yes & $60,0 \%$ & $47,0 \%$ & $72,0 \%$ & $15,4 \%$ & $6,5 \%$ & $24,2 \%$ \\
\hline
\end{tabular}




\begin{tabular}{lllllll}
\hline Health Insurance & & & & & \\
Contributory. & $48,0 \%$ & $39,0 \%$ & $58,0 \%$ & $18,0 \%$ & $10,8 \%$ & $25,2 \%$ \\
Without health insurance. & $70,0 \%$ & $55,0 \%$ & $85,0 \%$ & $43,2 \%$ & $27,0 \%$ & $59,5 \%$ \\
Subsidized. & $58,0 \%$ & $35,0 \%$ & $47,0 \%$ & $20,0 \%$ & $15,3 \%$ & $24,7 \%$ \\
\hline Hours Worked Month & & & & & & \\
$<100 \mathrm{~h}$ & $57,0 \%$ & $43,0 \%$ & $71,0 \%$ & $14,9 \%$ & $4,6 \%$ & $25,2 \%$ \\
$101-160$ & $43,0 \%$ & $28,0 \%$ & $59,0 \%$ & $24,4 \%$ & $11,0 \%$ & $37,7 \%$ \\
$161-220$ & $53,0 \%$ & $40,0 \%$ & $65,0 \%$ & $13,6 \%$ & $5,3 \%$ & $22,0 \%$ \\
$221-570$ & $59,0 \%$ & $53,0 \%$ & $65,0 \%$ & $24,6 \%$ & $19,4 \%$ & $29,8 \%$ \\
\hline
\end{tabular}

Table 3 shows a multivariate analysis taking into account: the consumption of liquor in general, the consumption of low level of alcohol and later the harmful consumption of alcohol. In this sense, by age groups, we do not find any significance, but there is a trend that those who consume alcohol with mild intensity are those under 40 years and those who have harmful consumption are those between 40 and 60 years. As for gender, men are clearly at greater risk of consumption than women. In addition, it is striking that those who have health insurance by the government, have a greater risk of being light consumers, but this was not reflected in those harmful consumers. It is well known that the fact of smoking is clearly linked to the consumption of liquor either at the general level, mild or harmful. Although it was true that those who lived in the capital city of the area had a greater risk of being consumers of liquor, when it was broken down by level of consumption, the risk was not significant. In terms of psychometric, the Cronbach's alpha for audit test was. 80 and Cronbach's alpha calculated for the Fagerstrom test was.64.

Table 3. Variables according to multivariate model about the consumption of alcohol on street vendors in the Metropolitan Area of Bucaramanga

\begin{tabular}{|c|c|c|c|c|c|c|c|c|c|c|c|c|}
\hline \multirow[t]{2}{*}{ Variables } & \multicolumn{4}{|c|}{$\begin{array}{l}\text { Not consumers and all who } \\
\text { consume alcohol }\end{array}$} & \multicolumn{4}{|c|}{$\begin{array}{l}\text { Non-consumers vs Low } \\
\text { alcohol consumption }\end{array}$} & \multicolumn{4}{|c|}{$\begin{array}{l}\text { Non-consumers vs Harmful } \\
\text { alcohol consumption }\end{array}$} \\
\hline & OR & CI & & $p$ & OR & CI & & $p$ & OR & CI & & $p$ \\
\hline \multicolumn{13}{|l|}{ Age Groups } \\
\hline $18-39$ & 1 & & & & & & & & & & & \\
\hline $40-59$ & 0.78 & 0.4 & 1.3 & 0,4 & 0.51 & 0.2 & 1 & 0.06 & 2.23 & 0.7 & 6.7 & 0.1 \\
\hline $60-82$ & 0.46 & 0,1 & 1,1 & 0.1 & 0.49 & 0.1 & 1.3 & 0.1 & 0.71 & 0.07 & 7 & 0.01 \\
\hline \multicolumn{13}{|l|}{ Gender } \\
\hline Female & 1 & & & & & & & & & & & \\
\hline Male & 4.83 & 2.67 & 8.72 & $<0.01$ & 4.36 & 2.2 & 8.4 & $<0.01$ & 4.26 & 1.2 & 14.4 & 0.02 \\
\hline \multicolumn{13}{|c|}{ Occupational Risk Administrator } \\
\hline No & 1 & & & & & & & & & & & \\
\hline Yes & 2.29 & 1,1 & 4,6 & 0.02 & 1.92 & 0.8 & 4.3 & 0.1 & 2.06 & 0.5 & 7.4 & 0.2 \\
\hline \multicolumn{13}{|l|}{ Health Insurance } \\
\hline Contributory. & 1 & & & & & & & & & & & \\
\hline Without health insurance. & 2.56 & 0.8 & 7.5 & 0.08 & 2.51 & 0.6 & 9.2 & 0.1 & 1.57 & 0.2 & 9.1 & 0.6 \\
\hline Subsidized. & 3.27 & 1.5 & 6.9 & 0.02 & 3.67 & 1.5 & 8.8 & $<0.01$ & 1.47 & 0.4 & 5.4 & 0.5 \\
\hline \multicolumn{13}{|l|}{ Smoking } \\
\hline No & 1 & & & & & & & & & & & \\
\hline Yes & 4.24 & 2.3 & 7.5 & $<0.01$ & 3.35 & 1,7 & 6.4 & $<0.01$ & 8.77 & 2.9 & 26.2 & $<0.01$ \\
\hline
\end{tabular}




\section{Capital of the State}

\begin{tabular}{lllllllllllll} 
No & 1 & & & & & & & & & & & \\
Yes & 1.78 & 1.01 & 3.22 & 0.05 & 1.56 & 0.8 & 3 & 0.1 & 2.80 & 0.8 & 9.5 & 0.09 \\
\hline
\end{tabular}

\section{Discussion}

In the world there are not many studies available that attempt to cover the issue of street vendor's health and work conditions. Particularly, the present study identified a high consumption of cigarettes and liquor added to a strong relationship between both habits. In addition, no significant figure was found on the harmful consumption of cigarettes and alcohol. According to the multivariate analysis, the factors related to the consumption of any liquor were: cigarette consumption; being a man; have health insurance subsidized by the government; smoke and live in the capital city of the Metropolitan Area.

According to sociodemographic variables and particularly in the gender approach, we note that our findings suggest that most of the workers interviewed had an even gender distribution, with an average age prone to maturity. Given the above, the ILO says that women have greater participation in the informal sector globally speaking (International Labour Organization, 2002). For example, in regions like India it is not clear how much is the amount of women sellers, except in Ahmedabad where about 40\% of the 80000 street vendors are women. In turn, in most cases women work in this job because of poverty and because male family members are unemployed, such as in Vietnam and Cambodia (Bhowmik, 2005). Therefore, it would be interesting to generate more research on gender approach studies in the informal sector especially considering the culture, the social environment and the family of the working woman.

In turn, our data shows that a large proportion of workers have health coverage pertaining to government-subsidized regime. For example, in a recent publication has highlighted how important and necessary is to have a coverage of health services in Africa, Asia and Europe, the article commented that health insurance is required for this type of work, and to some extent this will improve coverage in their protection towards financial risks (Muiya \& Kamau, 2013). Given the above, it is vital that all workers have health insurance, because over the years people tend to increase the risk of developing diseases. In our study at the beginning of the multivariate analysis, we contemplated the hypothesis that those workers without health coverage could be more at risk of being harmful consumers of alcohol and cigarettes, however this relationship was not proven, this assumption was derived from some studies that offer information on the vulnerability of these workers in terms of access to health services. (Daovisan, Promphakping, \& Chamaratana, 2018) (Lund, Alfers, \& Santana, 2016). Moreover, it is highlighted that this situation was going to be reflected in the future as unhealthy people with bad quality of life (Mendizabal \& Tufiño, 2014; Muñoz \& Chois, 2013). Given the above, it becomes necessary that all informal workers are aware of the benefits of having a health insurance instead of looking at it as a mere requirement.

In addition, it was found that a health insurance was one of the variables of risk associated with harmful alcohol consumption, for example in Vietnam: Less than half of the workers in the informal sector were willing to pay for health insurance. The willingness to pay was affected by gender, economic status and health status of respondents. In turn, there was a trend of adverse selection in health insurance for this group of workers (Thu-Huyen \& Van-Minh, 2014). Also, in our study, low coverage in terms of occupational risk was found, but no significant statistics regarding this assurance. Therefore, it would be interesting to conduct in-depth studies that show from the economic point of view, the distribution of money spent on alcohol consumption, cigarette, basic needs and health insurance or occupational hazards for the street worker. For example, in Ghana, the main factor for not having health coverage was the cost of these insurance policies in occupational health (Alfers, 2013).

According to the measures of association in Table 3 and the multivariate logistic regression, we can also conclude that according to harmful alcohol consumption, the risk variables include into the model were age between 40-60 years; not having health insurance; smoking and living in the capital city of the Metropolitan Area. Moreover, the gender variable behaved as a confounding variable, so this situation was taken into account when making the adjustment. Likewise, when reviewing alcohol consumption taking the critical values of the AUDIT scale, this score is higher in men. However, after adjusting for confounding variables, the only variables related to harmful liquor consumption from the point of view of statistical significance were the smoking variable and sex male.

In relation to smoking, it is interesting to note that in the bivariate analysis, those who reported being cigarette consumers accounted for a fifth of the respondents and the main variables related were: male people under 40, married, without coverage risks occupational and health and whose working hours are greater than 220 per month. Publications available on the consumption of cigarettes in general workers are centered in groups of companies 
focused on formal work, although some publications in Latin America in informal vendors reported cigarette consumption between 10 and 30\% (Viveros, Vivas, \& Guerrero, 2014; Ardila \& Rodriguez, 2013), although there are no studies specifically in street vendors. In turn, in a study in Asia, 80 informal vendors smokers were enrolled, $47 \%$ were smokers, noting that the main task of this exhibition was dedicated to public transport (Kirana, Kresna, Barkinah, \& Isnaniah, 2014). Therefore, in terms of public health, it is relevant to develop strategies to raise awareness on the harmful use of alcohol and smoking in terms of health promotion and prevention of the possible development of chronic non-communicable diseases.

Among the strengths of the study, we can say that the sample size was superior to many of the papers presented, however we could cite as a limitation that a probability sampling was not carried out. However it is important to note that to achieve probability sampling in such workers, a fairly demanding methodological challenge is required, what leads to invest a greater amount of time and budget according to the objectives. Another important limitation could be recall bias that the participants may have had when answering questions about their own consumption of liquor and cigarettes, but in terms of the properties of the scales used, the values of internal consistency ranged from. 64 and. 80 what are acceptable scores in the validity of the tests.

As for the specific field of occupational medicine, our work can offer the following lessons. First, the doctor must recognize in an informal street vendor the lack of protection they have in terms of their health and safety at work. We found in our study that consumers of liquor in general have a low health insurance and on the other hand, we find an important relationship in smoking and being a harmful liquor consumer. All possible combinations of the three variables mentioned can lead to workers not having adequate well-being, not only from the physical aspect but also from the psychosocial aspect. Second, it is important that the occupational physician knows some of the main short questionnaires to detect patients with substance dependence such as cigarette and liquor. This is important, since in the medical consultation, the doctor should not only rely on a dichotomous response of the patient, but must go far beyond finding valid information about consumption or not. While such surveys are not diagnostic, their information is valuable above all as a technique or method for screening.

In conclusion, the street vendors have certain socio-demographic and labor variables conducive to raising their vulnerability. As for their spending habits, they have a high consumption of cigarettes and alcohol in relation to other groups of workers, however the level of dependence is not superlative, but in those who had detrimental alcohol consumption the most important related variables to intervene would be the insufficient health coverage and smoking.

Finally the important role of street vendors in the economy of each country has been published, but in many cases instead of recognizing their contribution to the economy, they are typecast as invaders or criminals (Bhowmik, 2005). At the same time, it is important to recognize the economic and social benefits that lead to a healthy workforce, for this reason it is necessary examine deeply the benefits that informal workers offer within a country's economy, on the other hand it is necessary to create and strengthen public policies around all the occupations that involve informality.

\section{Acknowledgements}

This study had the support of students from the Occupational Health Specialization at Manuela Beltran University at Bucaramanga, who contributed in the development of the research.

\section{Competing Interests Statement}

The authors declare to have no conflict of interest.

\section{References}

Alfers, L. (2013). The Ghana National Health Insurance Scheme: Barriers to Access for Informal Workers. WIEGO. Woman in Informal Employment Globalizing and Organizing. Policy brief, (9), 1-6.

Ardila, C. P., \& Rodríguez, R.M. (2013). Health conditions and work of the informal working population in displacement Bucaramanga, Colombia. Investig andina, 15(26), 628-639.

Babor, T., Higgins-Biddle, J.C., Saunders, J.B., \& Monteiro, M. (2001). The Alcohol Use Disorders Identification Test Guidelines for Use in Primary Care Second Edition. World Health Organization, Department of Mental Health and Substance Dependence, 1-40.

Beco-a, E., \& Vasquez, F. L. (1998). The Fagerström Test for Nicotine Dependence in a Spanish sample. Psychological Reports, 83(3), 1455-1458.

Bhowmik, S. (2005). Street Vendors in Asia: A Review. Econ Polit Wkly, May-June, 2256-2264. 
Botina, N., Cabrera, M. E., Erazo, M. X., Guerrero, M. C., Ibarra, M. F., Vallejo. F. et al. (2011). Caracterización de las condiciones sociodemográficas laborales y de salud en los trabajadores informales del sector agrícola del Municipio de Tangua departamento de Nari-o. 2011. [Characterization of labor sociodemographic and health conditions in the informal agricultural workers of the Municipality of Tangua Nari-o, 2011 Research for the degree in Occupational Health]. CES University.

Contreras, M., González, R., \& León, S. (2014). Health self-care in informal sector female workers in Guadalajara (Mexico). A gender perspective. Revista Salud Uninorte, 30(1), 1-9. https://doi.org/10.14482/sun.30.1.4309

DANE. Departamento Nacional de Estadística . The National Administrative Department of Statistics. (2009) Metodología informalidad, Gran Encuesta de Hogares - GEIH. Methodology informality, Great Household Survey. December. Bogotá Colombia.

DANE. Departamento Nacional de Estadística. The National Administrative Department of Statistics. (2013a). Proyecciones de población municipales 2006 -2020. Informe. Bogotá: DANE Colombia. 2013.

DANE. Departamento Nacional de Estadística. The National Administrative Department of Statistics. (2013b) Informe de Coyuntura Económica Regional. Regional Economic Situation Report. Bogotá Colombia.

DANE. Departamento Nacional de Estadística. The National Administrative Department of Statistics. (2014). Medición del empleo informal y seguridad social Trimestre móvil Marzo - Mayo 2014, Bogotá Colombia. Measurement of informal employment and social security mobile Quarter March-May 2014, Colombia.

Daovisan, H., Promphakping, B., \& Chamaratana, T. (2018). Selling labor-domain livelihood assets: A qualitative approach to non-subcontracting home-based garment workers in the Lao PDR. Kasetsart Journal of Social Sciences. https://doi.org/10.1016/j.kjss.2017.12.021

Guallpa, D. (2015). Prevalencia de hipertensión arterial y factores asociados en comerciantes del mercado el arenal, Cuenca 2014. Prevalence of hypertension and associated factors in market traders El Arenal, Cuenca 2014. Research work for obtaining the title of specialist in internal medicine, 1-51.

Heatherton, T., Kozlowsy, L., Frecker, R., \& Fagerstrom, K.O. (1991). The Fagerstrom Test of Nicotine Dependence: a revision of the Fagerstrom Tolerance Questionnaire. British Journal of Addiction, 86, 1119-1127. https://doi.org/10.1111/j.1360-0443.1991.tb01879.x

ILO. International Labour Organization. (2002). Women and Men in the Informal Economy: A Statistical Picture (pp. 1-60). Geneva,. $\quad$ Retrieved from http://www.ilo.org/dyn/infoecon/docs/441/F596332090/women\%20and\%20men\%20stat\%20picture.pdf

ILO. International Labour Organization. (2003) Report of the Seventeenth International Conference of Labour Statisticians (pp. 1-108). Geneva, November- December.

ILO. International Labour Office. (2013). Global Employment Trends (pp. 1-107). Recovering from a Second Jobs Dip; ILO Geneva.

Kirana, R., Kresna, V., Barkinah, T., \& Isnaniah, B. (2014). Smoking Behavior and Attitude Towards Cigarette Warning Labels Among Informal Workers in Surabaya City - East Java, Indonesia. https://doi.org/10.2139/ssrn.2419434

Kusakabe, K. (2006). Policy Issues on Street Vending: An Overview of Studies in Thailand, Cambodia and Mongolia. $\quad$ International Labour Office. Retrieved from http://www.ilo.org/wcmsp5/groups/public/---asia/---ro-bangkok/documents/publication/wcms_bk_pb_119_ en.pdf

Lund, F., Alfers, L., \& Santana, V. (2016). Towards an inclusive occupational health and safety for informal workers. NEW SOLUTIONS: A Journal of Environmental and Occupational Health Policy, 26(2), $190-207$. https://doi.org/10.1177/1048291116652177

Mendizabal, G., \& Tufi-o, B. (2014). Prestaciones de seguridad social para los trabajadores informales de la tercera edad en México. Social security benefits for informal workers in Mexico Seniors. Revista Internacional y comparada de relaciones laborales y derecho del empleo, 2(4), 1-20.

Ministerio de Salud, Congreso de la República de Colombia. (1993). Resolución por la cual se establecen las normas cientificas, técnicas y administrativas para la investigación en salud (pp. 1-12). [Resolution by which scientific research and administrative health standards are established techniques]. Bogotá, Colombia.

Moyano, E., Guevara, R. C., \& Lizana, J. (2008) Informal work: Motives, well-being, health and happiness in 
street vendors. Psicol em Estud. 13, 693-701.

Muiya, B.M., \& Kamau, A. (2013). Universal health care in Kenya : Opportunities and challenges for the informal sector workers. Int J Educ Res., 1(11), 1-10.

Mu-oz, A., \& Chois, P. (2013). Health and informal trade in Cauca, Colombia. Rev. Fac. Nac. Salud Pública, 31(1), 09-18.

Orozco, H. B., Barreto, I., \& Sánchez, V. (2008). Street sellers attitudes of Chapinero neighbourhood about their working and political conditions. Diversitas, 4, 279-290.

Thu-Huyen, D.T., \& Van-Minh, H. (2014). Willingness to pay for health insurance among informal sector workers : A case study from Hanoi capital Vietnam. Vietnam Journal of Public Health, 2(1), 24-31.

Viveros, J., Vivas, M., \& Guerrero, N. (2014). Health and Work Health and Work Conditions for People Working Informally in the Agricultural Sector in Popayán, Colombia. Rev Virtual Univ Católica del Norte, 41(1), $112-122$.

Wellman, R.J., Savageau, J.A., Godiwala, S., Savageau, N., Friedman, K., Hazelton, J., \& DiFranza, J. R. (2006). A comparison on the Hooked on Nicotine Checklist and the Fagerström Test for Nicotine Dependence in adult smokers. Nicotine and Tob Res, 8(4), 575-580. https://doi.org/10.1080/14622200600789965

World Medical Association. (2008). Declaration of Helsinki, Ethical Principles for Medical Research Involving Human (pp. 1-5). Retrieved from http://www.wma.net/es/30publications/10policies/b3/17c_es.pdf

\section{Copyrights}

Copyright for this article is retained by the author(s), with first publication rights granted to the journal.

This is an open-access article distributed under the terms and conditions of the Creative Commons Attribution license (http://creativecommons.org/licenses/by/4.0/). 